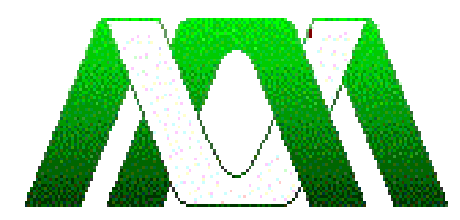

Casa abierta al tiempo

UNIVERSIDAD AUTÓNOMA METROPOLITANA

UNIDAD IZTAPALAPA

DIVISIÓN DE CIENCIAS SOCIALES Y HUMANIDADES

POSGRADO EN CIENCIAS ANTROPOLÓGICAS

Organización política de los coras antes y después de su reducción en 1722.

Laura María Magriñá Ocampo

ENSAYO

PARA OBTENER EL DIPLOMA DE ESPECIALIZACIÓN

EN ANTROPOLOGÍA POLÍTICA

Director: Dr. Roberto Varela Velázquez 


\section{Organización política de los coras antes y después de su reducción en 1722}

\section{Introducción}

\subsection{La conformación de la sociedad cora}

El lapso -de casi dos siglos- entre 1531 y 1722, abarca el dinámico proceso de conformación de una sociedad "compuesta" que surge justamente del contacto entre diferentes grupos indígenas y los colonizadores, y de la resistencia tanto a la conquista como a la evangelización.

En el siglo XVIII, el Gran Nayar comprendía básicamente la región cora, es decir, la zona rebelde, insumisa, de la sierra del Nayarit -que también incluía a algunos tecualmes aún no pacificados (Ortega, 1996 [1754]: 201)-, y a los huicholes asentados al norte de la provincia de Huaynamota -pues los huicholes de Colotlán (Arias de Saavedra apud Calvo, 1990 [1673]: 264 y 286287), los totorames de la franja costera norteña del actual estado de Nayarit, los sayaguecos del noreste de Ixcuintla y los huaynamotas, entre otros, ya estaban "pacificados", o por lo menos bajo el relativo control de mineros y de los franciscanos de la provincia de Xalisco (Arregui, 1946 [1621]: 12). Y, debido a los constantes levantamientos de los tepehuanos, éstos ya eran objeto de una rigurosa vigilancia por parte de los franciscanos de la provincia de Zacatecas, quienes, tras la rebelión del Mixtón, siempre iban acompañados de soldados (Calvo, 1990: 275).

Posiblemente los coras -en tanto sociedad "compuesta"- surgieron de antiguos habitantes de la sierra, así como de los costeños y alteños que huyeron a la irrupción de Nuño Beltrán de Guzmán en 1531 y, sobre todo, de la voluntad de resistencia a la conquista española de los derrotados de la guerra del Mixtón en 1541 (Mota Padilla, 1973 [1870] (1742): 458). Esos refugiados de diferentes procedencias -tanto geográficas como culturales- se congregaron en el territorio serrano y lograron un acomodamiento político viable. En este sentido su capacidad de adaptación y refuncionalización culturales fue definitiva. El macizo serrano constituyó, efectivamente, un bastión en contra de los intentos por evangelizarlos y conquistarlos.

En general, se tiene la idea de que la belicosidad de los coras fue una de las principales causas de su conquista tardía; sin embargo, ellos la utilizaron como una de sus estrategias fundamentales de preservación autonómica y fueron alternativamente indios de guerra e indios de paz, dependiendo de la circunstancia. 
Uno de los aspectos que fue clave para la conquista tardía, y que en gran medida se ha pasado por alto, es el hecho de que el Gran Nayar fuese tierra de todos y tierra de nadie. Las diferentes instancias de la administración colonial se deslindaban de la responsabilidad, cuando les convenía, y se adjudicaban como propios los triunfos y beneficios de la zona. Un territorio sin dueño oficial específico puede usarse como pretexto o justificación de muchas acciones.

El que la sierra del Nayarit hubiera sido tierra de nadie -en términos administrativo, eclesiástico y militar- fue aprovechado por los coras para controlar las rutas comerciales, crearse fama de aguerridos y adoptar diferentes estrategias, según el interlocutor en turno. Así, se apropian del espacio a través del control de las rutas de comercio y caminos de acceso a la serranía y no es sino hasta la llegada de los jesuitas que esta zona cambia de dueño. Por lo tanto, para nuestros "indios de guerra" la estrategia principal fue la apropiación del territorio y el control del comercio.

La abrupta topografía contribuyó, sin duda, a la libertad política de los coras, mas no a su autonomía económica, pues dependían de los productos agrícolas del altiplano del actual estado de Nayarit y principalmente pesqueros y salineros de su costa. Su "realidad" social estaba en gran medida regida por las relaciones con el entorno colonial, básicamente por vía del comercio y en distintas épocas la sierra fue un adecuado lugar de refugio para gente tanto de cercanas como de lejanas comarcas de la Nueva España.

El método franciscano de evangelización para el Gran Nayar no fue sistemático ni profundo. Construyeron un cinturón de contención y mediante "bases de penetración" realizaban una predicación intermitente; Huaynamota, la única fundación en el interior de dicha región, fue efímera.

\subsection{Los jesuitas}

Los coras constituían un obstáculo para el control colonial de toda la región, por lo que las autoridades novohispanas, al considerar el buen desempeño que habían tenido los jesuitas en el septentrión y en California y el patente fracaso de los franciscanos en la región nayarita -además de las crecientes contradicciones que enfrentaba la orden seráfica con el clero secular-, eligieron a los misioneros de la Compañía de Jesús para la reducción religiosa de estos indígenas. La religión católica llegó al Gran Nayar junto con las armas, pues los jesuitas fueron acompañados por soldados. 
¿Qué hicieron los jesuitas para adueñarse del Gran Nayar? Tomaron el control total de la región con el apoyo militar. Tras su expulsión, los franciscanos ocuparon su lugar pero, aunque siguieron contando con soldados, no tuvieron la capacidad para apropiarse del territorio, por falta de tenacidad y organización de la orden seráfica; pero también contribuyó a su fracaso la política de secularización. Los misioneros de la orden seráfica pretendían convertir para controlar, a diferencia de los jesuitas que llegaron, en el caso del Gran Nayar, a conquistar para convertir.

A diferencia de los jesuitas del Noroeste, que impusieron un proceso civilizatorio técnico, los jesuitas del Gran Nayar implantaron un proceso fundamentalemente ideológico y social de evangelización, lo que implicó un reacomodo de pueblos y un "rompimiento" de la organización social cora.

Los jesuitas fundaron pueblos, en distintos momentos, durante su estancia en el Gran Nayar, entre 1722 y 1767, modificando así la geografía humana tras la conquista: Santa Rita de Cassia (en Peyotán), Santísima Trinidad (en La Mesa), Jesús María y José, Santa Teresa, Santa Gertrudis, San Francisco de Paula, San Ignacio Huaynamota, San Juan Bautista, San Pedro, Nuestra Señora del Rosario y Santa Rosa. Huaynamota, después de ser la única misión franciscana dentro del Gran Nayar, pasa a ser misión jesuítica (Ortega, 1996 [1754]: 199-200).

La forma de vida del indio es alterada; en cuanto a la economía, de cazadores recolectores y agricultores de subsistencia y de temporal, pasan a ser agricultores "sedentarios" porque son reducidos en pueblos; pero la información plasmada en los documentos muestra que en la práctica los coras "se huían" a su coamil para la cosecha y siempre fue difícil concentrarlos en los pueblos. Con respecto a la ideología, se les prohibe toda manifestación vinculada con su religión tradicional y se les obliga a adoptar el catolicismo; en este rubro también mantuvieron una constante resistencia y se aseguraron de preservar el costumbre (tradición religiosa de los indígenas) dentro del ámbito familiar. No tenían necesidad de construir pirámides teniendo tantos cerros, cuevas, fuentes de agua y rocas rituales, pero además, para facilitar la huida por la persecución de los misioneros jesuitas, los mitotes se realizaban en lugares apartados y ocultos y la parafernalia ritual, como el altar, por ejemplo, era desmontable.

Fue así como los coras se "adaptaron" a los jesuitas, quienes pretendían quedarse permanentemente, deseo que fue interrumpido por su abrupta expulsión en 1767. Posteriormente, aunque los franciscanos y el clero secular ocuparon esas misiones, la evangelización continuó de manera irregular ya que 
en esa época se sucedieron varias guerras y rebeliones. El largo período de alejamiento -doscientos años- durante los cuales los coras, principalmente, pero también los huicholes estuvieron fuera del contacto directo con los sacerdotes católicos, propició que las enseñanzas de los jesuitas fueran las que perduraran hasta nuestros días, aunque de una manera sui generis.

Sin embargo, las huellas de la evangelización jesuítica son evidentes, sobre todo, pero no exclusivamente, en el culto asociado al templo católico. Allí, los rituales se desarrollan con frecuencia sin sacerdote oficial y sólo bajo la dirección de los Mayordomos y Principales. Las imágenes correspondientes al santoral católico reciben un culto puntual, aunque vinculado a deidades aborígenes y los rezos y cantos en latín son todavía frecuentes.

\section{Metodología}

Lo político no es disociable de la cuestión económica, ni del ámbito religioso, ni de lo social (Evans-Pritchard, 1940: 90; Godelier, 1974: 244; Malinowski, 1976 [1974]: 93; Sahlins, 1976 [1974]: 233 y Plattner, 1991 [1989]: 35); por lo que también la política de una sociedad se organiza simbólicamente. He aislado el comportamiento político de los coras tan sólo como un ejercicio metodológico, separando las piezas del rompecabezas con el objeto de alcanzar la comprensión por partes, para luego unirlas integrando la estructura social de este grupo indígena.

Presento dos cortes sincrónicos. El primero muestra la situación política de los coras que encontraron los jesuitas a su llegada en 1722; el segundo se refiere a la organización política implantada por los misioneros ignacianos durante sus primeros años en el Gran Nayar.

Para este análisis antropológico de la historia ha sido esencial el contar con un marco teórico más amplio que permita profundizar en la organización política de los coras. El modelo de Adams (1983 [1975] y Adams, apud Varela, 1999) -cuyos principios básicos comprenden la segunda ley de la termodinámica, que plantea que la energía no se destruye, se transforma; la selección natural, acerca de la sobrevivencia del más apto; la ley de Lotka, que conjuga las dos anteriores; y los principios de la física que establecen que las estructuras complejas surgen de otras más simples- ha sido de utilidad para desglosar los cambios que se fueron dando en la naturaleza de la organización social y política cora; esto es, los diferentes niveles de desarrollo que fui identificando conforme me acercaba al siglo XVIII. Por otra parte, la teoría 
individualista de Blau (1964) funciona, en ciertos aspectos, de la misma manera para las colectividades; por lo tanto, el intercambio social también corresponde a acciones voluntarias de proporcionar bienes, motivadas por la expectativa de reciprocidad, transacción que pone en juego la diferenciación de poder al dar bienes o favores superiores a cambio de inferiores, creando así futuras obligaciones (Blau, 1964: 91-93).

Debido a que la sociedad estudiada no contaba con instituciones políticas propiamente dichas, los conceptos acuñados por Turner ilustran de manera clara nuestra unidad de análisis. Así, ante la rigidez que pudiera representar el concepto de estructura, he optado por abordar la temática desde el punto de vista de un campo político -lugar donde se dan los procesos, que alberga a los actores sociales; y arena política, el espacio privilegiado donde se presenta el conflicto (Turner, 1974: 127-128 y 133)-, dada la sensación de expansióncontracción y fluidez que brinda este concepto, pero también porque engloba justamente la idea de este proceso dinámico de desarrollo y transformación gestado durante casi dos siglos por la sociedad "compuesta" que nos ocupa.

Tanto el trabajo etnográfico de Gluckman en Zululandia, como el análisis que realiza sobre los zulúes a partir de un sinnúmero de "... libros, comunicaciones y reportes sobre Zululandia en los últimos 100 años" (1940: 25), han sido fundamentales para este ensayo. Su preocupación central es el conflicto en las relaciones sociales, entre grupos de cooperación (Gluckman, 1978 [1965]: 307). Aunque sus análisis acerca de los "conflictos en el ritual" se refieren a sociedades africanas, sus propuestas son directamente pertinentes para el tratamiento de ciertos casos de las culturas del Gran Nayar.

De la Peña define a los gitanos de Madrid como una sociedad "encapsulada" (1970: 11), concepto que resulta de suma utilidad para describir la situación de los coras tras la llegada de los jesuitas al Gran Nayar.

Otros trabajos etnográficos que brindaron un marco de comparación para delimitar mi objeto de estudio, con base en el conocimiento empírico de los distintos tipos de sociedades, fueron los de Lévi-Strauss, 1967 (1944); Marshall, 1967 (1960); Sahlins, 1994 (1968 [1961]); Lee, 1968; EvansPritchard, 1979 y Varela, $1984 a$ y $1984 b$.

Mi objeto de estudio es la acción política (Varela, 1984: 20-21) y las relaciones de dominación y sujeción que en ésta se presentan entre los distintos sujetos sociales. Por tanto, la finalidad de este ensayo es analizar el desarrollo del sistema de relaciones de poder de los coras entre 1531 y 1722, con el fin de conocer, por un lado, qué tipo de organización social y campo político tenía este grupo étnico al momento de ser reducido por los jesuitas y, por el otro, la 
transformación que éste sufre en el primer momento del contacto, tras la conquista en 1722.

Cuatro hilos conductores han guiado este estudio: el flujo energético, entendido como proceso de transformación del trabajo; el concepto central del poder, es decir, la capacidad de toma de decisiones (Adams, 1983 [1975 (1950)]: 21); la amenaza, siempre presente, como la posibilidad de ejercer coerción (Bierstedt apud Adams, 1983 [1975 (1950)]: 21); y por último, el control.

\section{Análisis}

\subsection{Los coras entre 1531 y 1722}

El poder es una relación sociopsicológica derivada del "control relativo" ejercido por cierto actor o unidad operativa sobre los recursos materiales significativos -que forman parte de un ambiente que incluye los aspectos social, material y físico- para otra u otras personas (Adams, 1983 [1975]: 26 y 29). Debido a que no se puede controlar a quien no comparte de alguna manera la misma cultura, estos recursos deberán ser culturalmente aceptados y reconocidos. Los jesuitas tuvieron primero que conocer a los coras para saber cuáles eran sus recursos significativos y luego proceder a controlarlos (controlar un símbolo brinda poder simbólico; lo que cambia en el poder es la base, ésta puede ser también económica, política o simbólica).

El poder reside en el dominio, en el liderazgo y en los controles relativos (Adams, 1983 [1975]: 26), y depende de la tasa de flujo energético (Ibídem: 28); a más energía corresponde una mayor concentración de poder. El campo político de los coras no tuvo un ingreso energético constante, sino que fue transformándose a medida que el ingreso se incrementaba y así fue que alcanzó un nivel mayor de complejidad en el siglo XVIII.

Aun cuando éste no es un estudio de caso, pues no se cuenta con la información documental específica y suficiente, en la sociedad nayarita se dan las condiciones propuestas por Blau (1964) para que una persona pueda ejercer el poder, las cuales son desarrolladas por Varela en su estudio de Tlayacapan, Morelos (1984a: 35-36) y por De la Peña, en su investigación sobre los gitanos de Madrid (1970: 39). 
1. Que esa persona acapare recursos que son necesarios para la comunidad.

2. Que los miembros de la comunidad no puedan adquirir esos recursos de otras fuentes.

3. Que los miembros de la comunidad no puedan corresponder con otros intercambios equivalentes a dicha persona.

4. Que los miembros de la comunidad no puedan tomar por la fuerza esos recursos.

5. Que los miembros de la comunidad no puedan prescindir de esos recursos.

De hecho, es posible deducir la presencia de estas cinco condiciones a partir de datos dispersos; por ejemplo, la capacidad de los coras de convocar a sus jefes con el fin de realizar un despliegue de poder y de su fuerza guerrera, que describe Solchaga. El jesuita Thomás de Solchaga, acompañado de don Gregorio Mathias de Mendiola, del capellán don Francisco Xavier Pardo, de treinta soldados españoles y de cien indios amigos, entraron al Gran Nayar, en 1715, para "recibir la obediencia, que los Naturales Nayeritas ofrecian dar al Rey nueftro Señor Don Phelipe V" (Solchaga, apud Ortega, 1996 [1754 (1715)]: 63) y para solicitar su reducción a la fe católica. Primero, los hicieron esperar 20 días "para que fe juntaffe toda la Nacion" (Ibídem: 64). Posteriormente, fueron recibidos por una embajada de 400 indios jóvenes, menores de treinta años, "todos desfigurados con el tinte que llaman embije, que trahían no folo en el roftro, fino en el cuerpo, que parecian Demonios; ivan todos armados de arcos, y flechas, y con plumages de varios colores en las cabezas en forma de coronas" (Ibídem: 65-66). Los condujeron a una "cafilla de paja con varias piezas, y divifiones, que eftava aorillada al barranco del rio. [...] veíamos los cerros, que coronavan aquel fitio, llenos de gente, que havia concurrido, para vér nueftra entrada" (Ibídem: 66). Allí pasaron la noche y al día siguiente fueron por ellos para salir a recibir a

los Señores, Grandes, y Viejos del Nayar [...] fe acercaron hafta aviftarfe à nofotros dos filas de hombres armados, que llegarian à quinientos, fobrandoles gente para rodearnos en circulo, lo que nos tuvo rezelofos, por no paffar de ciento, y treinta los Nueftros. Al remate de eftas dos filas venia la Nobleza, y Magnates del Nayerit: trahían en medio dos Viejos, que eran como fus Sacerdotes; eftos venian fin armas, y en medio de ellos iva fu Reyefuelo, ò Governador mozo, que 
trahía en la cabeza una corona de variedad de plumas bien matizadas, y en la mano un bafton con la empuñadura de plata: era alto de cuerpo, y bien aperfonado, pero de tanta feveridad, que declinava à ceño. Rodeavanle doze Capitanes, y todos trahían coronas en las cabezas de viftofas plumas, algunas de ellas armadas fobre cintillos de plata. Otros fobre las coronas tenian unas medias Lunas, y otras figuras tambien de plata. Acompañavales affimifmo una mufica tan acorde, y harmoniofa, que todos creìamos, que era un Organo portatil (Solchaga, apud Ortega, 1996 [1754 (1715)]: 66-67).

En el período inicial -de la situación posterior a la conquista de la Nueva Galicia, pero previo a su sometimiento- los coras conformaban una sociedad sin Estado, con una situación similar a la de los !Kung, cazadores-recolectores. Aunque la subsistencia de los coras ya tenía como eje la agricultura de temporal, los reacomodos de la post-guerra del Mixtón determinaron un peso inusual para la subsistencia a los productos de la recolección y la cacería, así como a las eventuales adquisiciones por incursiones de rapiña a territorios vecinos. El factor habitacional era determinante para sus relaciones (Lee, 1968: 87). Posiblemente, ellos también en caso de sequía solían compartir, en lugar de proceder a la división de los grupos o a la competencia entre ellos (Ibídem). Lo que unía a los miembros de las bandas era únicamente la necesidad de la subsistencia del grupo.

Ante la insuficiencia de datos, no es factible hablar de niveles de segmentación, aun cuando pareciera que los segmentos primarios serían los grupos de familiares con un líder (Sahlins, 1994 [1968 (1961)]: 101); me parece más adecuado proponer que los coras, al igual que los Nambikuara, cultivaran en época de lluvias y fueran errantes durante las secas, desintegrando las bandas en grupos parentales para facilitar la sobrevivencia, dada la carencia de los recursos alimenticios (Lévi-Strauss, 1967 [1944]: 49-50). Por un lado, no contaban con un extenso territorio por donde pudieran circular libremente pues estaban rodeados por otros grupos indígenas "chichimecas", así que se desplazaban, pero dentro de un perímetro determinado; por otra parte, muchos de ellos, provenientes de otras regiones, se habían refugiado en la sierra.

Considero que los coras, con relativa rapidez, se fueron sedentarizando, ya que fue institucionalizándose la distribución de los territorios para fines de la agricultura de roza, tumba y quema. Sería aventurado intentar establecer cierta periodización, pero las fuentes documentales nos permiten constatar que ya en 1604 los coras practicaban la agricultura mediante la misma técnica usada hoy 
en día de roza, tumba y quema (Del Barrio, apud Calvo, 1990 [1604]: 272); los franciscanos que entraron por Huazamota ilustran sobre la gran variedad de frutas que vieron en el Gran Nayar -plátanos, aguacates, cañas, ciruelas, zapotes y tunas, entre otras- en 1619 y 1622 (Pérez y Obantes, apud Calvo, 1990 [1619 y 1622]: 275-277); mencionan que, hacia 1650-1653, los coras sembraban mucho maíz (Tello, 1968 [1650-1653]: 42); y cómo no dejaban descansar sus tierras, principalmente en "Tzacaymuta y Mymbre", donde tenían "milpas y árboles frutales como son duraznos, membrillos, platanales, tunales y nogales y cañas dulces", camotes, papas y frijoles (Arias de Saavedra, apud Calvo, 1990 [1673]: 289).

Las características de cada sociedad dependen de sus condiciones de vida y de su propia historia (Lévi-Strauss, 1967 [1944]: 45), y las jefaturas correspondientes varían entre sí en su forma, pero comparten la misma función, el liderazgo (Ibidem: 47 y 51). Según Lévi-Strauss, el desarrollo de una banda se debe al potencial de su líder (Ibídem: 51).

En una banda se encuentra el nivel mínimo de concentración de poder (Lévi-Strauss, 1993 [1949]: 168 y 178; Fox, 1972 [1967]: 229). La totalidad del poder era asignada al jefe por el grupo cora, así que en cualquier momento éste le podía ser retirado. Su único recurso para mantener el cargo era mostrarse dadivoso con la comunidad; como no había explotación del trabajo porque la base de subsistencia era la agricultura de temporal y el suplemento alimenticio se obtenía de la recolección, de la caza y también de la pesca, el único excedente que el jefe obtenía era resultado del trabajo de sus esposas y de los dones que le brindaba la gente, el cual redistribuía inmediatamente. Por eso el Nayarit (el Tonati) era tan pobre según el testimonio de fray Miguel de Uranzu hacia 1607 (Magriñá, 1999: 151).

En la poliginia la estrategia ${ }^{1}$ central es la acumulación de mujeres, de ahí las ventajas tanto de coras como de huicholes de tener idealmente cinco esposas; existe una jerarquización entre ellas, porque cumplen funciones económicas específicas. La acumulación de bienes puede proporcionar prestigio $-\mathrm{y}$ si éste está ritualizado, demostrará mayor proximidad con las deidades- lo cual, a su vez, permitirá extraer cierto excedente de los demás. Esta cadena propicia un sistema de jerarquización que es al mismo tiempo un sistema político, de relaciones sociales de producción y de estructura mitológica (Magriñá, 1999: 297-298).

\footnotetext{
${ }^{1}$ La estrategia "se refiere a la asignación de recursos y al plan de acción globales" (Adams, 1983 [1975]: 33), a diferencia de la táctica, que va en función de un plan inmediato y a pequeña escala (Ibidem).
} 
El jefe no tenía el control del comportamiento social, ya que éste estaba regulado por la propia conducta de los individuos quienes, en caso de conflicto, hacían justicia por su propia mano (Arias de Saavedra, apud Calvo, 1990 [1673]: 293).

Al igual que entre los !Kung, las bandas nayaritas debieron ser autónomas una respecto de la otra (Marshall, 1967 [1960]: 19), pero se unían tanto para la guerra contra los huaynamotas, como para el ritual (Magriñá, 1999).

Tanto sus requerimientos como su desgaste energético eran reducidos, pero los coras fueron incrementando sus ingresos energéticos $-\mathrm{y}$ su evolución social alcanzó el nivel de jefaturas- a partir de la adopción de elementos técnicos de origen asiático y mediterráneo, así como del intercambio comercial -principalmente de mezcal destilado, que elaboraban localmente, y de sal y pescado seco, que adquirían en la costa e intercambiaban por otros productos en los reales de minas-, de la incipiente ganadería, posiblemente del cobro de peaje a otros indígenas serranos por el uso de sus caminos, y la venta de fuerza de trabajo en las haciendas y minas; además, de que fueron ganando territorio de los huaynamotas por vía de la guerra (Magriñá, 1999: 210-221). Aquí vemos cómo el manejo de la tecnología, por ejemplo, implica un conjunto de conocimientos, habilidades y capacidad de organización del trabajo en función del control sobre el ambiente del "otro" y su asimilación, donde "... la palabra control se refiere a la toma y ejecución de decisiones acerca del ejercicio de una tecnología" (Adams, 1983 [1975]: 29).

No es posible hablar de una sola y única jefatura, debido a que el Tonati nunca operó como el jefe supremo de todos los coras. Su debilidad está patente en el temor que tenía de que los mismos serranos le quitaran la vida si aceptaba bautizarse (Ortega, 1996 [1754]: 91).

Paulatinamente, el prestigio, primero del caudillo Naye en 1500 (Ortega, 1996 [1754]: 9), luego del cacique indígena Coringa en 1549 (Pascual, apud Román, 1993 [1549]: 106-111), y más tarde del Nayarit, se extiende a nivel regional como el jefe de una tribu, es decir, de una coordinación de bandas. Sin embargo, no se trata de centralización de poder; cada banda tenía su jefe y el poder del Nayarit era relativo. El ritual fue adquiriendo cada vez más fuerza. Recordemos que para una sociedad que cuenta con agricultura de temporal, la incertidumbre por las lluvias es mucho mayor; de ahí el vínculo tan fuerte entre agricultura, cosmovisión y ritual. Por ejemplo, se celebraban mitotes en La Mesa del Tonati, a donde asistía un gran número de coras. 
A medida que la organización social y política de los coras iba evolucionando, se requirió cada vez más de los trabajos comunitarios y del ritual, pues el incremento del flujo energético trajo consigo una mayor redistribución y los mitotes eran los rituales por excelencia para este fin, que adquirían también la función catártica. De esta manera, el ritual va teniendo cada vez más influencia hasta llegar a ser un factor clave para la centralización del poder. El poder es también "... necesario para el mantenimiento de la sociedad contra las presiones del desorden y el caos" (Balandier, apud Adams, 1983 [1975 (1970)]: 23) y, además de la guerra constante contra los huaynamotecos, para los coras estaba ya latente el peligro de ser conquistados por la administración novohispana. Así, en momentos de conflicto y tensión las bandas se unían activando la coordinación y luego volvían a su estado de centralización. Por lo tanto, a mayor presión del exterior, correspondió un incremento de poder y una mayor capacidad de toma de decisiones.

\subsection{El período jesuítico}

A su llegada al Gran Nayar, los jesuitas se encontraron con una confederación de jefaturas similar a la de los shilluk (Evans-Pritchard, 1979). Durante la toma militar de La Mesa del Tonati, quien la defiende es el cacique Tlahuitole, debido a que el Tonati se hallaba fugitivo por temor a ser asesinado por los jefes coras quienes, molestos porque él había pactado con el virrey, lo acusaban de haberse aliado a los españoles; planeaban matarlo y sustituirlo por un cacique viejo, pero este último fue tomado preso por los soldados. Mucho tiempo después regresó el Tonati a La Mesa con todas las garantías y seguridad por parte de los españoles (Ortega, 1996 [1754]: 143, 152 y 187).

Los jesuitas aprovechan la capacidad de los jefes para controlar los recursos energéticos y sobreponen a ellos sus estructuras de poder. La sociedad indígena queda, entonces, "encapsulada" (De la Peña, 1970: 11) dentro de la esfera del conquistador, en la que también se encuentran los militares, pues no son un grupo aparte, sino el aparato de control de los jesuitas.

Se generan nuevas lealtades ${ }^{2}$ y alianzas - a distintos niveles- de los coras, tanto con los jesuitas como con los militares. ${ }^{3}$ Las relaciones pueden

\footnotetext{
${ }^{2}$ Sobre la división de lealtades, Gluckman considera que “... para que los conquistadores puedan alcanzar una posición de estabilidad deben entablar relaciones con los súbditos que eliminen la división entre ellos y dividan a los súbditos entre sî” (1978 [1965]: 140).
} 
considerarse como normas sociales bajo las cuales los colonizadores y los colonizados "adaptan su comportamiento recíprocamente" (Gluckman, 1968 [1958]: 10). El "conflicto de lealtades" reside en que muchas de ellas son contradictorias entre sí (Gluckman, 1940: 54). Existen relaciones personales e impersonales; en el nivel personal se dan relaciones amistosas entre los individuos de ambos grupos, donde "... la amistad y cooperación son la norma social, afectada por la norma más amplia de separación social" (Ibídem: 19). Es imposible que se integren en términos de igualdad; los dos grupos (dominadores y dominados), socialmente aceptados como dos categorías, se asocian -en relaciones de hostilidad, separación, conflito y colaboración- con base en la explotación o la cooperación (Ibídem: 12-13). Ambas esferas se distinguen ".. por diferencias de color y raza, de idioma, creencias, conocimientos, tradiciones y posesiones materiales" (Ibídem: 13).

Pero es interesante, cómo -a la manera que describe De la Peña (1970: 11) para los gitanos de Madrid- en el caso cora, estos indígenas también tienen un acercamiento con las otras etnias de la región y acomodan su conducta según la persona o grupo con quienes interactúan. La reducción de los coras funge como el detonador de los cambios que se sucedieron en estas tierras. Con la unificación, pues oficialmente ya todo era territorio conquistado, las políticas de control por parte de las autoridades coloniales y las prácticas de resistencia indígena se generalizan. Desaparece, así, la necesidad de contar con "indios fronterizos", quienes a la postre, perdieron sus prerrogativas.

La resistencia a la evangelización se puede comprender desde la pespectiva del "caso ampliado" de Gluckman, a partir del análisis de las relaciones sociales en conflicto "de principios y valores opuestos" en un período de tiempo largo para constatar cómo "... los varios grupos y partidarios actúan con y manipulan las creencias místicas de diferentes tipos para sus intereses" (1978 [1965]: 280). Por otra parte, Gluckman considera que la presión ejercida por los conquistadores, en su intento por eliminar las creencias, puede ser un factor importante “... para su mantenimiento bajo los procesos de endocultura como un valor grupal" (1968 [1958]: 75).

La reducción de los coras coincide con un período de conflicto y de sequía, por lo que en 1722 la organización política de este grupo étnico se encuentra en una etapa de transición, que se activaba fundamentalmente en momentos de ritual o de conflicto. En la gráfica (cfr. Figura 1) se muestra la

\footnotetext{
${ }^{3}$ Tomemos el ejemplo de don Juan de la Torre, quien estuvo a cargo de la primera etapa de la conquista en 1722, que tenía -en 1729- refugiados en su casa, cerca de Jerez, a "una docena de indios" coras que se habían fugado (Meyer, 1989: 52).
} 
situación económica en diferentes momentos de la historia: en 1711, fray Antonio Margil de Jesús visita el Gran Nayar y se encuentra con una sociedad indígena en pleno auge (Magriñá, 1999: 137); hacia 1720, observamos un marcado descenso de los recursos energéticos, debido al período de sequía por el que atravesaba la región cora (Meyer, 1989: 27), que propició que asaltaran a sus vecinos y éstos bloquearan la ruta de la sal (Magriñá, 1999: 135-136 y 217-219); para 1722 ya es patente el impacto de la guerra de conquista; $y$ hacia 1730, los misioneros relatan la bonanza alcanzada y sus éxitos evangelizadores. El objetivo de mi investigación doctoral es, precisamente, desentrañar qué tan verídicos son los informes de los jesuitas y analizar la situación política, socioeconómica y religiosa del Gran Nayar durante este período.

En las sociedades tribales, la cooperación exige relaciones más estrechas e interdependientes entre sus miembros y una riña o la violación de una norma tiene allí efectos más profundos que en la sociedad industrial (Gluckman, 1978 [1965]: 290 y 304). "La característica dominante de estas sociedades es que la gente interactúa con una misma serie de personas para conseguir propósitos diversos" (Ibídem: 304).

Como entre los zulúes, el control social de los coras se ejerce a través de las deidades, los antepasados, la brujería y la magia (Gluckman, 1978 [1965]: 269). "El culto a los antepasados sirve para controlar las relaciones entre los parientes vivos" (Ibídem: 270) y los ancianos son el vínculo entre los antepasados y la comunidad. El grupo doméstico o unidad productiva parental no es una unidad de producción y consumo autárquica, porque entre los coras existe la cooperación, reciprocidad e intercambio entre los distintos grupos domésticos; éstas son las redes de relaciones que conectan a las familias entre sí, vinculando el parentesco con la comunidad (Sahlins, 1976 [1974]: 234-237). Tenemos desde pequeñas rancherías de asentamiento disperso, con unos cuantos grupos domésticos, hasta "numerosas" rancherías (Ortega, 1996 [1754]: 184) de asentamiento semidisperso, con varios grupos domésticos. Existe un jefe por ranchería, institución a la que denomino "jefatura"; obviamente, unas son más eminentes que otras.

Al igual que en Zululandia, en la primera etapa colonial la tarea fundamental era mantener el orden y, posteriormente, se puso énfasis en el desarrollo de las reservas de recursos energéticos (Gluckman, 1968 (1958): 15). Durante el período jesuítico la concentración de la producción agrícola no es total, debido a que el producto del coamil es mayoritariamente consumido por la unidad doméstica; una pequeña porción es intercambiada entre las distintas familias; y las ganancias del comercio de los coras que intercambian a 
larga distancia, son reinvertidas por los mismos comerciantes indígenas. Así pues, lo que se obtiene, como un tipo de tributo, de los grupos domésticos y de la producción comunitaria, aunado al ingreso que viene de donativos a través de la misma Compañía de Jesús, y el suministro de la Hacienda Real -cuando éste llega- por vía del virreinato, es centralizado por los jesuitas y redistribuido para su propia manuntención y la de los militares. Además, la mano de obra indígena es aprovechada para la construcción de los templos -y de los presidios: San Francisco Xavier de Valero en La Mesa, San Salvador el Verde en Santa Gertrudis, y el del Santo Cristo de Zacatecas en Huaynamota (Doye, apud Meyer, 1989 [1745]: 91 y Ortega, 1996 [1754]: 169-200)-, el cuidado de la iglesia, las obras públicas y la conservación de la misión y del pueblo (con variantes según la comunidad, su contexto y el momento histórico).

Se constata en las fuentes documentales el descontento de los indígenas con los misioneros "... porque los afligían mucho con el trabajo que les daban" (AGN, Provincias Internas, 127, ff 421-469, apud Meyer, 1989 [1758-1759]: 159). Obviamente, los indios que trabajaban en las iglesias de las misiones no recibían ningún tipo de pago por sus servicios (Bugarín, apud Meyer 1993 [1768]: 66).

En toda la provincia no había ninguna hacienda (Bugarín, apud Meyer 1993 [1768]: 68). Y está patente en los documentos la resistencia de los jesuitas de "... dar cuadrillas de indios para trabajo en las Minas" (Polo, apud Meyer, 1989 [1764]: 166) y el enojo de los mineros de Durango, Guadalajara y Zacatecas contra los jesuitas del Gran Nayar por no permitirles abusar de la mano de obra cora (Meyer, 1997: 53). Además, la mano de obra escaseaba principalmente en tiempo de aguas, cuando los indígenas se iban a su coamil. El apoyo de las autoridades coloniales les fue retirado a los jesuitas del Gran Nayar, justamente porque estos misioneros no se alinearon con los intereses de los mineros y hacendados (Meyer, 1989: 164-181 y 1993: 17-18).

Varios militares tenían recursos independientes obtenidos a partir del trabajo de los coras, pero también como producto del botín. Asimismo, en el sector indígena - de la misma manera que sucedía antes de su reduccióntenemos también que algunos individuos, pertenecientes a distintos grupos domésticos, cuentan con recursos independientes que provienen de la caza, la pesca, la recolección y el intercambio comercial. 


\section{Conclusión}

\subsection{La organización política de los coras}

Los coras controlaron su medio ambiente y se relacionaron con los demás grupos serranos y con sus vecinos del altiplano y de la costa; desde el siglo XVI recibieron influencia simbólica y tuvieron la capacidad de adoptar los elementos técnicos introducidos por los conquistadores en las regiones que circundaban al Gran Nayar; pero mantuvieron su autonomía política y religiosa por casi 200 años.

Mucho antes de la llegada de los españoles a los alrededores del Gran Nayar, los coras se encontraban organizados en bandas (Lee, 1968; Marshall, 1967 [1960]) integradas por grupos domésticos seminómadas. El jefe tenía muy poca capacidad de toma de decisiones, pues estaba a expensas de la voluntad de la comunidad, ya que en cualquier momento le podían retirar el poder asignado. Su cargo era eminentemente simbólico y el control que ejercía iba en función de lo generoso que fuera, pues lo que recibía tenía que darlo a los miembros de la banda en reciprocidad. Los coras contaban con recursos energéticos mínimos que empleaban al máximo.

Así, en el período comprendido entre 1531 y 1722 he identificado tres tipos de sociedades dependiendo de sus características. En la primera fase de conformación, como sociedad "compuesta", de este grupo étnico, -que considero de transición, porque se activaba fundamentalmente en momentos de ritual o de conflicto- nos encontramos ante una tribu, es decir, una coordinación de bandas (Lévi-Strauss 1967 [1944] y Sahlins 1994 [1968 (1961)]) que se unían, principalmente, frente a la amenaza del exterior, ya fuera por parte de los huaynamotas -sus acérrimos enemigos autóctonos- o de los conquistadores europeos.

En la segunda fase de desarrollo, tenemos jefaturas con agricultura de subsistencia, caza, pesca y recolección, con una incipiente ganadería y una amplia red comercial, en las que ya hay cierto excedente. Dado que se ha incrementado el flujo energético, tanto el control que ejerce el jefe como su capacidad de toma de decisiones son mayores pues, además del poder que le es asignado por el grupo, ya cuenta con ciertos recursos independientes. Una diferencia importante con respecto a la fase anterior es que el jefe detenta también el poder mágico religioso, y como el ritual ya ha adquirido gran peso, éste justificará y reforzará la centralización del poder. 
Y la tercera -al igual que a la primera fase, la considero de transición porque se activaba fundamentalmente en momentos de ritual o de conflicto- es una confederación de jefaturas a la manera de los shilluk (Evans-Pritchard, 1979), como un estadio intermedio entre una jefatura y un reino (Gluckman, 1978 [1965]: 107-109). El peso está en la jefatura, no en el jefe en sí mismo; ya existe el cargo como tal. El Tonati equivaldría al rey, quien generalmente detentaba menor poder que los jefes. Ortega menciona 50 de estos jefes -25 de ellos acudieron con el Tonati a la ciudad de México para pactar con el virrey(1996 [1754]: 80-81). Recordemos que cada jefatura requería de la fuerza concentradora del ritual para reforzar el poder. Ésta es justamente la organización política que encontraron los jesuitas a su llegada al Gran Nayar.

\subsection{La organización política implantada por los jesuitas}

En el período jesuítico se dan nuevos roles interjerárquicos. Como el Tonati está fuera del campo político, los jesuitas sobreponen su estructura de poder a la de las jefaturas. Los jefes quedan, entonces, en un plano intermedio entre los colonizadores y los coras, pero no como intermediarios políticos, puesto que siguen perteneciendo al grupo de los indígenas en tanto superiores a éstos, pero quedan como súbditos del grupo de los misioneros (Varela, 1984: 51-52), recibiendo a su vez poder delegado de los jesuitas y poder asignado de los coras.

Tras la reducción de los coras, el dogma ya no tiene el rol centralizador de poder para los jefes, pues el costumbre se reproduce en el ámbito familiar exclusivamente y el mitote se realiza a escondidas en lugares apartados. Los jesuitas, por su parte, ejercen más el control coercitivo que el dogmático, aun cuando la evangelización es el eje principal de la centralización de su poder.

Con la llegada de los conquistadores, en cierta forma, los jefes son los más directamente afectados. El poder mágico religioso les es arrebatado por los misioneros y tienen la doble presión de recibir poder delegado de los jesuitas y poder asignado de los coras (Varela, 1999 [1996]: 267). Generalmente la toma de decisiones para el ejercicio de ambos poderes resulta contradictoria. Los jefes, que habían accedido al poder básicamente por sus atributos guerreros, de alguna manera, estaban siendo cuestionados; así, ellos son los que propician y organizan los constantes levantamientos. Mientras tanto, los grupos parentales conservan autonomía en cuanto al control de gran parte de sus recursos energéticos. 
Aunque los coras sufrieron una conquista política y religiosa, es interesante observar cómo en este proceso la voluntad del indio no fue borrada, ya que su comportamiento cuenta para la estabilidad del grupo hegemónico. Los coras eligen situacionalmente las normas y valores que los regirán, aunque ya todos los habitantes del Gran Nayar tienen las mismas normas, ellos escogen una u otra según la situación (De la Peña, 1970: 46).

El modelo de Gluckman (1940, 1948 y 1965) es útil para demostrar que el sistema político durante el período jesuítico está conformado por cooperación y conflicto entre los coras y los jesuitas, en la medida en que se trata de la "encapsulación" (De la Peña, 1970: 11) de una sociedad en otra y ambas interactúan recíprocamente.

Asimismo, el plantemiento teórico de Gluckman sobre los zulúes ilustra también el paso de una confederación a una centralización entre los coras, antes y después de su reducción, respectivamente.

Bajo una nueva estructura de organización social, los jesuitas lograron la apropiación tanto de los recursos naturales como de los “... energéticos (personas y cosas)" (Varela, 1984b: 271), a partir del ejercicio de la actividad económica con un tipo diferente de racionalidad, excluyendo de los beneficios de la explotación de la mano de obra indígena a los mineros y hacendados de las zonas aledañas al Gran Nayar.

En el Gran Nayar el período jesuítico es de suma importancia, porque, los elementos culturales que impusieron aquellos misioneros sentaron las bases de la matriz cultural de los coras contemporáneos, en la medida en que, paradójicamente se conjuntaron dos fuerzas opuestas. Por un lado, la expulsión de los jesuitas -que truncó el proceso evangelizador y que no pudo continuarse ni por el clero secular ni por los franciscanos-; por el otro, la resistencia indígena a la conquista religiosa y militar -mediante la estrategia sincrética de adaptación y reacomodo de los elementos católicos en su cosmovisión; la aparente sumisión, evadiendo recibir los sacramentos y no asistiendo a misa; y la respuesta armada ya que, de haber aceptado pasivamente su reducción, no habrían realizado tantos levantamientos y alborotos (Meyer, 1989: 13, 159, 161, 163, passim).

Recapitulando, vemos cómo, en el segundo corte sincrónico, las modificaciones se presentan en el dogma, pues el costumbre es sustituido -a nivel público- por el catolicismo tridentino; en el flujo energético, esto es, en el proceso de transformación del trabajo, ya que la población indígena es reducida en pueblos y -a nivel comunitario- se reorganizan la producción agrícola y el trabajo indígena en función de las misiones jesuíticas; en la capacidad de toma 
de decisiones de los jefes, pues es alterada por la nueva jerarquía sobrepuesta a su acción política; en la amenaza, siempre presente, como la posibilidad de que los jesuitas -a través de los soldados- ejerzan coerción y, por último, en el paso de las manos de los jefes a las de los jesuitas del control de los recursos energéticos para la estructuración del poder (Varela, 1984b: 271). 


\section{Bibliografía}

Adams, Richard Newbold, Energía y estructura. Una teoría del poder social, Fondo de Cultura Económica, México, 1983 (1975) (Sección de Obras de Sociología).

Arias de Saavedra O.F.M., Antonio, "Información rendida por el P. [...] acerca del estado de la Sierra del Nayarit, en el siglo XVII", Los albores de un nuevo mundo: siglos XVIXVII, (Thomas Calvo, editor), Centre d'Études Mexicaines et Centraméricaines Universidad de Guadalajara, 1990 (1673): 284-309 (Colección de Documentos para la Historia de Nayarit I).

Arregui, Domingo Lázaro de, Descripción de la Nueva Galicia, (François Chevalier, edición y estudio), Hijos de A. Padura, Sevilla, 1946 (1621), (Publicaciones de la Escuela de Estudios Hispano-Americanos, XXIV, serie 3a, 3).

Barrio O.F.M., Francisco del, "Relación de las cosas sucedidas en las serranías de choras y tepehuanes e de las costumbres y rritos destas naciones y de la disposición y sitios de sus tierras", Los albores de un nuevo mundo: siglos XVI-XVII, (Thomas Calvo, editor), Centre d'Études Mexicaines et Centraméricaines - Universidad de Guadalajara, 1990 (1604): 256273 (Colección de Documentos para la Historia de Nayarit I).

Blau, Peter, Exchange and Power in Social Life, John Wiley \& Sons, Inc., Nueva York, 1964.

Calvo, Thomas, Los albores de un nuevo mundo: siglos XVI y XVII, Universidad de Guadalajara - Centre d'Études Mexicaines et Centraméricaines, México, 1990 (Colección de Documentos para la Historia de Nayarit I).

De la Peña, Guillermo, Settled Gypsies in Madrid, tesis de maestría en antropología, Department of Social Anthropology, Faculty of Economic and Social Studies, University of Manchester, Manchester, 1970.

Evans-Pritchard, E. E., The Nuer, Clarendon Press, Oxford, 1940.

- - -, “La realeza divina de los shilluk del Sudán”, Antropología política, (J. R. Llobera, compilador), Editorial Anagrama, Barcelona, 1979: 297-316 (Biblioteca Anagrama de Antropología, 12).

Fox, Robin, Sistemas de parentesco y matrimonio, Alianza Editorial, Madrid, 1972 (1967) (Alianza Universidad).

Gluckman, Max, "The Kingdom of the Zulu of South Africa", African Political Systems, (M. Fortes y E.E. Evans-Pritchard, editores), Oxford University Press, Lóndres, 1940: 2555. 
- - , Analysis of a Social Situation in Modern Zululand, Manchester University Press, Manchester, 1968 (1958).

- - -, Politics, Law and Ritual in Tribal Society, Basil Blackwell, Oxford, 1971 (1965).

---, Política, derecho y ritual en la sociedad tribal, Akal Editor, Madrid, 1978 (1965)

(Manifiesto, Serie de Antropología).

Godelier, Maurice, Economía, fetichismo y religión en las sociedades primitivas, Siglo XXI Editores, México, 1974: 223-255.

Lee, Richard B., "What Hunters do for a Living, or, How to make Out on Scarce Resources", Man in Adaptation: the Cultural Present, (Yehudi A. Cohen, editor), Aldine, Chicago, 1974 (1968): 87-100.

Lévi-Strauss, Claude, "The Social and Psychological Aspects of Chieftainship in a Primitive Tribe: The Nambikuara of Northwestern Mato Grosso", Comparative Political Systems, (R. Cohen y J. Middleton, editores), The Natural History Press, Nueva York, 1967 (1944): 4562.

- - -, Las estructuras elementales del parentesco, volumen I, Planeta-Agostini, Barcelona, 1993 (1949).

Magriñá, Laura, Los coras entre 1531 y 1722. ¿Indios de guerra o indios de paz?, tesis de licenciatura en etnohistoria, Escuela Nacional de Antropología e Historia, México, 1999.

Malinowski, Bronislaw, "La economía primitiva de los isleños de Trobriand", Antropología y economía (Maurice Godelier, editor), Editorial Anagrama, Barcelona, 1976 (1974): 87100 (Biblioteca Anagrama de Antropología, 6).

Marshall, Lorna, “!Kung Bushman Bands", Comparative Political Systems, (R. Cohen y J. Middleton, editores), The Natural History Press, Nueva York, 1967 (1960):15-43.

Meyer, Jean, El Gran Nayar, Universidad de Guadalajara - Centre d'Études Mexicaines et Centraméricaines, México, 1989 (Colección de documentos para la historia de Nayarit, III).

- --, (editor) Visita de las misiones del Nayarit 1768-1769 por el cura José Antonio Bugarín, Centro de Estudios Mexicanos y Centroamericanos - Instituto Nacional Indigenista, México, 1993.

- - -, "24 de junio de 1767", La Jornada, Sección Sociedad y Justicia, México, lunes 30 de junio de 1997: 53. 
Mota Padilla, Matías de la, Historia del Reino de Nueva Galicia en la América Septentrional, Instituto Jalisciense de Antropología e Historia, Instituto Nacional de Antropología e Historia - Universidad de Guadalajara, Guadalajara, 1973 (1870 [1742]) (Colección histórica de obras facsimilares, número 3).

Obantes O.F.M., Rodrigo de, "[Fragmento del] Informe", Los albores de un nuevo mundo: siglos XVI-XVII, (Thomas Calvo, editor), Centre d'Études Mexicaines et Centraméricaines Universidad de Guadalajara, México, 1990 (1622): 277 (Colección de Documentos para la Historia de Nayarit I).

Ortega, Joseph de, S.J., "Libro I. Maravillosa Reduccion, y Conquifta de la Provincia de San Jofeph del Gran Nayar, nuevo Reino de Toledo", Apostólicos afanes de la compañía de Jesús, escritos por un padre de la misma Sagrada Religión de su provincia de México, (Francisco Javier Fluviá, editor), Edición facsimilar, con prólogo de Thomas Calvo y Jesús Jáuregui, Centro Francés de Estudios Mexicanos y Centroamericanos - Instituto Nacional Indigenista, México, 1996 (1754): 1-223.

Plattner, Stuart, Antropología económica, Alianza Editorial, México, 1991 (1989) (Los noventa).

Pérez Huerta O.F.M., Francisco, "[Fragmento del] Informe", Los albores de un nuevo mundo: siglos XVI-XVII, (Thomas Calvo, editor), Centre d'Études Mexicaines et Centraméricaines - Universidad de Guadalajara, México, 1990 (1619): 275-277 (Colección de Documentos para la Historia de Nayarit I).

Román Gutiérrez, José Francisco, "Situación de la orden franciscana en Nueva Galicia a principios del S. XVII", Actas del III Congreso Internacional sobre los franciscanos en el Nuevo Mundo (siglo XVII). La Rábida, 18-23 de septiembre, 1989. Archivo IberoAmericano. Revista trimestral de Estudios Históricos publicada por los pp. Franciscanos, Madrid, Segunda época, L, 197-200, 1990: 1179-1211.

Sahlins, Marshall D., "El linaje segmentario: una organización de expansión depredadora", Alteridades. La cultura de la pobreza: O. Lewis, año 4, número 7, División de Ciencias Sociales y Humanidades, Departamento de Antropología, Universidad Autónoma Metropolitana, Unidad Iztapalapa, México, 1994 (1968 [1961]): 99-113.

- - -, "Economía tribal", Antropología y economía (Maurice Godelier, editor), Editorial anagrama, Barcelona, 1976 (1974): 233-259 (Biblioteca Anagrama de Antropología, 6).

Torres, Francisco Mariano de, O.F.M., Crónica de la Sancta Provincia de Xalisco escrita por fray [...] 1755, H. Ayuntamiento de la ciudad de Guadalajara - Instituto Jalisciense de Antropología e Historia, Instituto Nacional de Antropología e Historia, Guadalajara, 1965 (1755) (Serie de historia, 7). 
Turner, Víctor, Dramas, Fields, and Metaphors, Cornell University Press, Ithaca y Londres, 1974.

Varela, Roberto, Procesos políticos en Tlayacapan, Morelos, División de Ciencias Sociales y Humanidades, Departamento de Antropología, Área de Relaciones Políticas, Universidad Autónoma Metropolitana, Unidad Iztapalapa, México, 1984a (Cuadernos Universitarios, 11).

- --, Expansión de sistemas y relaciones de poder, Departamento de Antropología, Universidad Autónoma Metropolitana, Unidad Iztapalapa, México, $1984 b$.

- - -, "La sociedad civil desde la antropología política", La sociedad civil: de la teoría a la realidad, (Alberto J. Olvera, coordinador), trabajos del seminario Sociedad civil, movimientos sociales y democracia, Centro de Estudios Sociológicos, El Colegio de México, México, 1999 (1996): 259-282. 